\title{
AS TRANSFORMAÇÕES DO CONCEITO DE INFÂNCIA EM "GRANDES ESPERANÇAS”, DE CHARLES DICKENS
}

Ricardo Maria dos Santos ${ }^{1}$

\section{Resumo}

O artigo discorre sobre as inter-relações entre as transformações do conceito de infância ocorridas até a segunda metade do século XIX na Inglaterra e as referências subjacentes a elas na obra "Grandes Esperanças" [Great Expectations] de Charles Dickens, usando material de pesquisa histórica e sociológica (Philippe Ariès, entre outros) e da fortuna crítica contemporânea das obras de Dickens.

Palavras-chave: Dickens; infância; "Grandes Esperanças”; criança crescida.

\section{Abstract}

The paper discusses the interrelationships between the transformations of the concept of childhood as they occurred up to the second half of the nineteenth century in England and the underlying references made to them in "Great Expectations", by Charles Dickens, resorting to historical and sociological research material (Philippe Ariès, among others) and also to the contemporary critical fortune of Dickens's works.

Key words: Dickens; childhood; "Great Expectations”; grown-up child.

\section{Introdução}

O presente trabalho tem por objetivo expor as inter-relações entre as transformações do conceito de infância que ocorreram até a primeira metade do século XIX na Inglaterra e seus possíveis reflexos na obra do romancista inglês Charles Dickens (1812-1870), especialmente com relação a obra Great Expectations [Grandes Esperanças].

\footnotetext{
${ }^{1}$ Professor da Faculdade de Ciências e Letras - Unesp/Araraquara-SP, Doutor em Letras pela Unesp.
} 
Tendo escrito quase toda sua obra no período de reinado da rainha Victoria, Dickens foi testemunha de uma época de intensas transformações sociais e culturais na sua Inglaterra natal, que viu consolidar o modelo econômico da Revolução Industrial e do então incipiente capitalismo moderno. Além disso foi um dos maiores criadores de personagens da Literatura Inglesa, entre as quais figuram alguns símbolos da nova sociedade que se delineava e, principalmente, algumas de suas vítimas. Com efeito, parte do grande poder oratório de sua ficção encontra suas raízes na indignação veemente com que o autor via certas modificações histórico-sociais, transformando tal sentimento em críticas que permeiam quase toda sua obra. Sua caracterização de personagens infantis se encontra entre as mais intensas da literatura até hoje - e a natureza do universo da criança em suas obras nos permite desenvolver vários pontos de reflexão sobre as dinâmicas relações entre seus textos e a sociedade inglesa vitoriana.

\section{Breve histórico do conceito de infância}

Para aprendermos com maior abrangência o conceito de infância a que nosso texto faz referência cabe-nos discorrer ainda que sucintamente, sobre seu desenvolvimento histórico. Reportaremos o que algumas obras de pesquisa contemporâneas dos campos sociológico e histórico apresentam de suas investigações na área da estruturação e história da família.

As diversas estruturas familiares que as sociedades humanas criaram se baseiam, numa simplificação didática, nas variações em torno da família nuclear (pai, mãe e filhos dependentes) e do maior ou menor afluxo de parentes (incluindo os filhos casados e suas proles) e até criados que a ela se juntavam, configurando desde famílias extensas (com praticamente todas as pessoas de uma mesma ascendência convivendo juntas) até clãs e tribos com regras de formação próprias. A relação entre essas famílias e o grupo social mais amplo em que elas se inseriam era estabelecida de acordo com as regras de hierarquia ditadas pelo poder econômico e político, vínculos de consanguinidade entre seus membros, linhas de descendência

e conseqüentes direitos de herança, e valores morais e religiosos vigentes na tradição da comunidade de que essas famílias eram sustentáculo. A relativa 
importância que as crianças têm em cada padrão de estrutura familiar varia naturalmente com esses valores e com o modus vivendi de cada sociedade.

O lugar da criança na sociedade européia ocidental foi marcado pelas mudanças que ocorreram lentamente a partir da Idade Média até meados do século XVII, quando seu papel na família passará a ter uma importância comparável a de nossa época. Philippe Ariès, no seu estudo sobre as diferentes interpretações que cada período da evolução humana atribuiu à infância, observa que:

[a]s classes de idade do neolítico, a paideia helenística, pressupunham uma diferença e uma passagem entre o mundo das crianças e o dos adultos, uma passagem que era realizada por meio da iniciação ou de uma educação. A civilização medieval não percebeu essa diferença, e, portanto, não possuiu essa noção de passagem.

Essa atitude em relação a criança explica-se por uma série de razões, segundo Ariès. Por questões demográficas, a alta mortalidade infantil e a grande fecundidade verificadas até a Idade Média não reservavam à criança um lugar especial nas relações da família: "a passagem da criança pela família e pela sociedade era muito breve e muito insignificante para que tivesse tempo ou razão de forçar a memória e tocar a sensibilidade". (p. 10)

Portanto, a criança teria um estatuto anônimo na sociedade medieval, pois mesmo que perecesse seria logo substituída por outra; além disso, não se via a criança como alguém com necessidades específicas de afeto e atenção, ainda segundo Ariès (p. 14): "A criança era portanto diferente do homem, mas apenas no tamanho e na força, enquanto as outras características permaneciam iguais." Até nas roupas essa diferenciação era flagrante: "Nada, no traje medieval, separava a criança do adulto. Não seria possível imaginar atitudes mais diferentes com relação a infância." (p. 70)

Atitudes assim eram típicas de uma sociedade em que a estrutura familiar havia se tornado extensa, reunindo às vezes três gerações numa mesma residência. Com as restrições religiosas do casamento entre pessoas com vínculos de parentesco

Ariès, P. História social da criança e da família. 2. ed. Rio de Janeiro: Jorge Zahar, 1978. p. 276. 
próximos, essa grande família perdeu muito de sua autoridade sobre seus membros, havendo então uma valorização da família nuclear, que se sujeitaria mais a autoridade da Igreja. Dessa forma,

\begin{abstract}
[a] gradual change toward the modern family took place in the late Middle Ages, with women and children being recognized as having rights of their own, independent of the head of the household, and with the emergence of the nuclear family or small, core kin group as the basic unit of both production and social life.
\end{abstract}

É interessante notar-se que, na arte pictórica, a criança passaria a ter uma representação mais especializada a partir do século XIII: é por volta dessa época que a iconografia das cortes européias de forte influência religiosa passa a mostrar a criança, inicialmente na figura de anjos, depois na do menino Jesus até chegar na iconografia leiga ao retrato e a presença recorrente do putto, a criancinha nua. Embora sempre tivessem feito parte de retratos de família, as crianças só passariam a ser retratadas sozinhas no século XVI, segundo Philippe Ariès. Essas representações confirmam o desenvolvimento de um sentimento de infância na sociedade européia, cujas famílias agora com um número reduzido de integrantes podem voltar-se para a criança com um grau de intimidade e atenção que só fará aumentar nos séculos seguintes.

Outro fator importante nesse contexto foi o da escolarização. Ao invés do sistema de aprendizagem, típico da Idade Média em que a criança e o jovem eram simplesmente colocados ao lado dos adultos para aprenderem um ofício e participarem da vida social houve uma crescente preocupação com a educação dessas crianças, de forma que elas foram retiradas do convívio social dos adultos, através da instituição do colégio hierarquizado no século XIV até chegar nos séculos XVIII e XIX ao sistema de internatos. Ao separar a criança do adulto, a sociedade reconhecia assim, o sentimento de infância que, ainda segundo Ariès (p. 157), "corresponde a consciência da particularidade infantil, essa particularidade que distingue essencialmente a criança do adulto, mesmo jovem."

FAMILY. Encyclopædia Britannica Online. Disponível em <www.members.eb.com>. Acesso em 21/01/2005. 
Houve na realidade uma separação também da própria família em relação ao grupo social; a família do século XVII, nuclear, composta dos pais e dos filhos ainda apresentará uma grande sociabilidade com o mundo exterior de forma que visitas e reuniões constantes ainda não permitirão a instauração de uma total intimidade entre a família e seus membros imediatos - muito diferente da família moderna:

\footnotetext{
A família moderna, ao contrário, separa-se do mundo e opõe a sociedade, o grupo solitário dos pais e filhos. Toda a energia do grupo é consumida na promoção das crianças, cada uma em particular, e sem nenhuma ambição coletiva: as crianças mais do que a família.
}

A valorização definitiva da infância ocorrerá com o advento do Romantismo no século XVIII. Umas das influências mais poderosas desse movimento foi o filósofo JeanJacques Rousseau, cujos escritos postulavam uma grande ênfase no sentimento, na intuição e, acima de tudo, na natureza e em tudo aquilo tido por natural. Sua asserção de que o ser humano nasce bom, mas a sociedade o corrompe daria origem a inúmeros desdobramentos na cultura européia. Uma de suas idéias mais importantes foi a do "bom selvagem" (beau sauvage): como o homem das civilizações ditas primitivas vivia sempre em contato com a natureza, ele seria 0 protótipo de pureza e bondade da natureza humana. Esse foco de interesse e de valorização sobre um passado e uma forma de viver idílicas, do ser humano em comunhão harmoniosa com o ambiente que o rodeava foi um dos traços definidores do movimento romântico na Europa e, por extensão, no mundo ocidental. Pelo mesmo raciocínio, a criança era um ser privilegiado, pois era muito nova e não havia sido corrompida ainda pelos costumes e convenções da sociedade. Essas idéias seriam artisticamente elaboradas nos poemas de um dos fundadores do movimento romântico inglês: William Wordsworth. Um de seus poemas mais famosos, publicado em 1802, serve para refletir o ethos do pensamento de seus contemporâneos:

\footnotetext{
My heart leaps up when I behold

A rainbow in the sky:

So was it when my life began;

So is it now I am a man;

So be it when I shall grow old,

Or let me die!

The Child is father of the Man;

And I could wish my days to be
}

Ariès, op. cit., p. 271.

Mediações - Revista de Ciências Sociais, Londrina, v. 10, n.1, p. 9-24, jan.-jun. 2005 AS TRANSFORMAÇÕES DO CONCEITO DE INFÂNCIA EM “GRANDES ESPERANÇAS", DE CHARLES DICKENS Ricardo Maria dos Santos 
O poema associa a evolução moral do adulto a sua infância; as características que esse adulto apresentará terão sido forjadas quando ele era criança. O poeta espera que a sensibilidade que ele tem desde pequeno, juntamente com sua emoção e percepção do mundo natural permaneçam quando ele envelhecer - do contrário, ele prefere a morte. Nesse exemplo é possível verificarmos a confluência de duas das principais idéias norteadoras do Romantismo: a importância da infância e da sensibilidade para com o mundo natural, constituindo assim, um dos legados que o poeta deve a Rousseau.

Boa parte da noção romântica de infância vem em substituição na verdade, ao impacto que o primitivismo causou e, na sua forma mais específica, ao ideal do Bom Selvagem. Entende-se o primitivismo como:

... the belief that man's greatest happiness and moral nobility was to be found in his original state, the "state of nature", and that his subsequent history - the history of advancing civilisation - has been one of gradual moral degeneration.

A essa crença se contrapunha o progressismo com forte enfase no papel da ciência e da técnica como expressões da superioridade racional de uma civilização avançada. Em seu estudo sobre Dickens, Malcolm Andrews discorre sobre como as noções de primitivismo e do progressismo mais se complementavam que se opunham e como elas deram lugar ao culto da infância. Isso ocorreu quando o mito do bom selvagem passou a encontrar resistências, a medida que se obtinham mais informações sobre os costumes e práticas dos povos indígenas; ao mesmo tempo, ainda havia uma forte crítica moral ao progresso material da sociedade inglesa, que era visto como desumanizador. Num primeiro momento, houve um certo culto à pobreza, vista não como miséria absoluta, mas meios honestos de se conseguir uma existência frugal. Com as incipientes revoltas de operários e o início da formação dos sindicatos, esse culto perdeu sua força, visto que havia então uma ameaça real ao poder estabelecido. Nesse contexto, a figura da criança aparece como solução ideal: ela traz em si a "infância da humanidade" (um substrato primitivista, portanto),

Andrews, Malcolm. Dickens and the Grown-up Child. lowa City: lowa University Press, 1994. p. 10. 
é universal (permite a inclusão de personagens da civilização européia e não somente de remotas culturas primitivas) e não traz ameaças à ordem política vigente.

Rastreando a influência de Rousseau sobre os autores e o clima político e cultural do final do século XVIII e começo do século XIX, Andrews analisa como a idéia do Bom Selvagem correspondia a uma certa nostalgia pelo passado pré-industrial da sociedade inglesa e pela decepção com as conseqüências da Revolução Industrial, tais como a pobreza extrema e a vil opressão de crianças e trabalhadores.

Tal opressão revela também uma situação contraditória: a criança pode ser elevada a uma categoria idealizada ou pode ser objeto de exploração conforme a classe social. As considerações que fizemos acima acerca da conquista de um lugar próprio para a criança se aplicam aos filhos das famílias das classes média e alta; as crianças vindas de famílias das classes mais baixas não tinham a oportunidade de ter sua especificidade levada em conta, uma vez que um dos impactos que a Revolução Industrial causou na estrutura familiar foi a exacerbação da exploração do trabalho infantil. Este, que não era de forma alguma uma novidade na história européia (de acordo com o historiador J. M. Roberts), adquiria no entanto características mais preocupantes:

\begin{abstract}
The difference made by industrialism was that their exploitation was regularized and given a quite new harshness by the institutional forms of the factory. Whereas the work of children in an agricultural society had perforce been clearly differentiated from that of adults by their inferior strength, there existed in the tending of machines a whole range of activity in which children's labour competed directly with that of adults. In a labour market normally over-supplied, these meant that there were irresistible pressures upon the parent to send the child into the factory to earn a contribution to the family income as soon as possible, sometimes at the age of five or six. The consequences were not only often terrible for the victims, but also revolutionary in that the relation of child to society and to the structure of the family were blighted.
\end{abstract}

Além de trabalhar longas jornadas fora de casa e estar exposta aos perigos envolvidos na operação das máquinas, a criança ainda fazia parte assim de um jogo econômico em que seus pais precisavam de seu trabalho e em que ela era uma

Roberts, John M. History of the World. New York: Oxford University Press, 1993. p. 571.

Mediações - Revista de Ciências Sociais, Londrina, v. 10, n.1, p. 9-24, jan.-jun. 2005 AS TRANSFORMAÇÕES DO CONCEITO DE INFÂNCIA EM "GRANDES ESPERANÇAS", DE CHARLES DICKENS Ricardo Maria dos Santos 
peça a mais para acirrar a disputa pela competitividade de mão-de-obra industrial numa época em que as cidades estavam com excedentes de trabalhadores vindos do campo. Nesses casos é também importante salientar, como já deixamos entrever acima, as diferenças de classe social subjacentes a importância que será dada à infância:

\begin{abstract}
Middle-class ideals held that children were innocents, to be educated and nurtured. Most working-class families urged a more traditional view of children as contributors to the family economy, but they too could see advantages in sending their children to school where possible and restricting their work in dangerous factories. Again, after the first decades of industrialization, reform laws began to respond. Legislation in Britain, France, and Prussia during the 1830s restricted the employment of young children in the factories and encouraged school attendance.
\end{abstract}

Como vemos, a "descoberta" da infância, com suas específicas necessidades, acabou por se impor, mesmo institucionalmente. Andrews analisa as mudanças pelas quais a infância passou a ser uma categoria a parte no ideário da sociedade da época. A maior longevidade da classe média tornava a infância um período cada vez mais curto da vida humana, mas com uma importância cada vez mais acentuada; a criança não era mais uma versão inferior a um adulto em tamanho e capacidade, mas possuía uma diferença em capacidade: ela tinha habilidades que seriam perdidas quando adentrasse a vida adulta. Uma aparente solução para isso era a idéia da "grown-up child" (criança crescida):

\begin{abstract}
Because, whatever the gains of adulthood - for example its access to the power structures of that society - there are important losses. The idea of the grown-up child emerges as this incompatibility is recognised. The ideal mature human would be one in whom the childlike virtues and powers coexist harmoniously with the adult's strengths, not one in which the grown person has wholly outgrown his childhood. The grown-up child, therefore, is a means of reconciling the primitivist and progressivist polarity as well as the adult-child polarity that emerges in the nineteenth century.
\end{abstract}

Uma dos efeitos mais nefastos da nova ordem econômica foi o aparecimento de bandos de crianças que perambulavam pelas ruas de Londres e de algumas grandes cidades inglesas, completamente abandonadas ou negligenciadas (pelas famílias e/ou poder público); a imprensa da época chamava-as de "selvagens", numa

HISTORY OF EUROPE. Encyclopædia Britannica Online. Disponível em <www.members.eb.com>. Acesso em 03/02/2005.

Andrews, M. op. cit., p. 25.

Mediações - Revista de Ciências Sociais, Londrina, v. 10, n.1, p. 9-24, jan.-jun. 2005 AS TRANSFORMAÇÕES DO CONCEITO DE INFÂNCIA EM "GRANDES ESPERANÇAS", DE CHARLES DICKENS Ricardo Maria dos Santos 
alusão a falta de qualquer controle ou orientação sobre suas vidas e a um comportamento associativo semelhante ao das tribos primitivas. Totalmente relegadas a própria sorte e fadadas a sobrevivência mais abjeta nas ruas das grandes cidades, elas tinham deixado de ser crianças e se tornaram pequenos adultos infratores. Se a existência delas aponta para a incongruência do ideal do Bom Selvagem numa estrutura social como a da época - e exigia soluções para corrigir tal aberração -, o ideal de educação da classe média, presente também na literatura infantil em contínuo crescimento, era basicamente de ordem pedagógica. $A$ educação das crianças deveria ser rígida, cientificista, baseada unicamente em fatos e ensinamentos de cunho moral e religioso, que prescrevia qualquer atenção mais detida a imaginação, aos circos, feiras e espetáculos de rua, a tradição oral (predominante nas classes mais baixas) e espontaneidade. Não é a toa que Dickens, severo crítico dessa perspectiva, haveria de retratá-la em Hard Times [Tempos Difíceis]. Na realidade, "by reaffirming the association of the child's simple, instinctive and uninhibited hedonism with these banished forms of entertainment, Dickens also made the child a potentially subversive figure in the new cultural climate". (p. 35)

Oscilando entre uma crítica ao ideário cultural de sua época, alimentado pelas correntes primitivista e progressista e uma rejeição a possíveis substitutos disponíveis nessa mesma época, Dickens reflete o complexo ideológico da atmosfera política e filosófica em que nasceu e na qual viveu. Essa atmosfera deve tanto mais ser levada em consideração quando há uma longa tradição da crítica de atribuir possíveis discrepâncias entre a visão de mundo de Dickens e suas criações ficcionais, exclusivamente às suas experiências traumáticas de infância. A confusão, por vezes incoerência e mesmo oposição entre elas também se constitui uma das heranças culturais a serem levadas em conta quando analisamos a gênese da obra do autor e as camadas de significado que seu texto apresenta.

\section{A criança na obra de Dickens}

O elenco de personagens infantis de Dickens é longo e variado. As crianças protagonistas de seus romances apresentam características diferenciadas pela 
concepção da obra, pelo estágio de produção estética do autor, pelos objetivos em relação a mensagem, analogias e paródias por parte do autor, e de toda a caracterização engendrada pelo uso do foco narrativo e da tematização particular de determinado texto. A isto se aliam concepções de caráter social, político e filosófico que estavam latentes, quando da criação do texto e imbricadas na atmosfera do período vitoriano em que Dickens viveu. Na literatura inglesa colocar uma criança no papel de protagonista de um romance para adultos era algo "virtualmente desconhecido" antes de Dickens publicar David Copperfield e The Old Curiosity Shop, como afirma Kathleen Tillotson.

As personagens Oliver, do livro Oliver Twist; David, de David Copperfield; a pequena Nell, de The Old Curiosity Shop [A Loja de antiguidades]; Paul Dombey, de Dombey and Son [Dombey e Filho], Jo, de Bleak House [Casa Soturna], e Pip, de Great Expectations [Grandes Esperanças] têm características que são moldadas pela forma peculiar como o autor as concebeu para figurar nas respectivas obras, e refletem a própria reação de Dickens ao mundo a sua volta e como sua visão de mundo instigava sua veia artística a produzir personagens que, em graus diversos de composição narrativa, incorporariam aspectos tópicos da realidade a que o autor dava voz. Em termos amplos, há um elemento fortemente romântico na construção das personagens infantis de Dickens, especialmente no período inicial de sua carreira. Assim é que Oliver e Nell permanecem imunes à corrupção do ambiente em que vivem - em Oliver Twist e The Old Curiosity Shop, respectivamente - e conseguem preservar uma pureza e virtude que vai ao encontro, na realidade, dos ideais de infância do público vitoriano, sendo freqüente a associação de crianças com imagens angelicais. No entanto verificamos que esses ideais já apresentam traços mais realistas, uma vez que Dickens caracteriza seus protagonistas como separados tanto da natureza quanto da "comunidade humana", nas palavras de $\mathrm{J}$. Hillis Miller:

The Dickensian hero is separated from nature. The world appears to him as cold and unfriendly, as a wilderness or a graveyard. In Dickens there is no Wordsworthian theory of the child's filial bond with nature. [...] The Dickensian hero is also alienated from the human community. He has no

Butt, John e Tillotson, Kathleen. Dickens at Work. London: Routledge and Kegan Paul, 1957. p. 79. 
familial tie. He is an orphan, or illegitimate, or both. He has no status in the community, no inherited role which he can accept with dignity. [...]

Dessa forma, a maioria das personagens infantis nos romances de Dickens sofre a opressão do mundo adulto, quer pela extrema pobreza a que são relegadas em instituições sociais (em Oliver Twist) pelo trabalho penoso que são obrigadas a realizar (como David Copperfield na fábrica de tintas) ou pelo desprezo e descrédito que suas necessidades afetivas enfrentam. A inflexibilidade dos adultos, como no caso de Mr. Murdstone em David Copperfield ou dos adultos que se reúnem no Natal em Great Expectations torna mais evidente, o desamparo presente nas relações entre as crianças e o mundo a sua volta, mesmo quando ainda têm parentes a cuidar delas - caso de Pip, que encontra bem pouco conforto nos cuidados da irmã, Mrs. Joe.

A caracterização da criança nos romances de Dickens permite discernirmos alguns aspectos da Weltanschauung do autor, como os conflitos filosóficos e políticos em curso na sociedade inglesa do período vitoriano, a que nos referimos na primeira parte deste artigo. $\mathrm{O}$ embate entre atitudes primitivistas e progressistas mostrava, como já vimos, diferentes interpretações para as questões morais advindas do ritmo intenso de transformações sócio-econômicas de que a Inglaterra era pioneira desde o início da Revolução Industrial até o século XIX. A inocência, virtude e extrema sensibilidade das personagens infantis deparavam com a corrupção, intolerância e até violência por parte dos adultos, e isto se não houvesse - como em Oliver Twisto perigo de não conseguir a própria subsistência, uma vez que ele nasce e é criado numa entidade social (a "workhouse", uma espécie de orfanato) em que a sobrevivência diária era incerta. Enquanto o relato das atribulações da infância reflete a posição da criança como vítima de diferentes flagelos - do abandono dos pais ou da sociedade, dos preceitos religiosos rígidos, da fragilidade dos próprios adultos em lhes dar proteção - , o crescimento dessas personagens traz à tona as complicações inerentes ao debate ideológico que pontuava as relações sociais da época, especialmente no que se referia ao estatuto da criança e do adulto.

Miller, J. Hillis. Charles Dickens: The World of His Novels. Cambridge, Mass.: Harvard University Press, 1958. p. 252. 
A relação criança - adulto é articulada nas obras de Dickens como o conflito entre duas fases do desenvolvimento físico, mental e psicológico das personagens em que características associadas a criança ou as mulheres de um lado são deliberadamente rechaçadas para se compor um padrão de comportamento masculino do outro. Muito do cientificismo então em voga parecia colidir - ou assim era sentido - contra a fantasia, a imaginação e a sensibilidade, denunciadas como atitudes não condizentes a um homem adulto que se pretendia dono de seu destino e pautado pela razão e objetividade. As dificuldades de David Copperfield e Pip, nesse contexto, ao ingressarem na vida adulta, seriam um reflexo e ao mesmo tempo resistência aos valores em mutação na sociedade vitoriana,

"[...] a culture which, for men particularly, promoted worldly sophistication and social status as the means of securing a share in the power structure, and which castigated as childish any failure to develop those qualities in the process of maturity."

Dessa forma, vê-se que tanto os empreendimentos de David quanto as várias tentativas de Pip de se posicionar no mundo de um gentleman em Londres remetem a esse imperativo cultural sub-reptício. O grande vigor com que David se aplica ao trabalho quando sua tia Betsey the revela não ter mais fontes de renda para sustentá-lo encontra paralelo no empenho de Pip ao se juntar a Herbert Pocket no Egito e trabalhar bastante até conseguir uma melhor posição na empresa. $O$ empenho ou a determinação em se dedicar com seriedade a uma meta ${ }^{2}$ era um dos valores que estavam se firmando na época de Dickens, segundo Andrews:

\begin{abstract}
This idea of earnestness is the single most important constituent of moral and intellectual maturity in Victorian middle-class terms, particularly for men. So too is the assumption, without complaint, of the role of provider and principal support for the family. Masculine maturity was evaluated according to the dedication and efficiency shown in assuming these responsibilities. This involved a positive relish for the hardships of life, a profound belief in the nobility of work, both as the means to an economic end and as a moral end in itself. (p. 162)
\end{abstract}

$\mathrm{Na}$ atitude de assumir para si um comportamento sóbrio nos termos que a classe média valorizava nos homens estava a implicação de abandonar traços

\footnotetext{
(Andrews, op. cit., p. 172.

${ }^{2}$ Assim parafraseamos a acepção do vocábulo inglês "earnestness" presente na citação.
} 
considerados incompatíveis com a nova imagem masculina; a rejeição absoluta de qualidades que até o período romântico anterior ao vitorianismo eram indiferentes na concepção das classes mais altas remete justamente a essa necessidade por parte da classe média inglesa de ter seus valores distinguidos daqueles dos estratos populares e aristocráticos. Muito do que a personagem Pip achará inadequado no comportamento de Joe e Biddy quando está de posse de sua fortuna mostrará na sua raiz, esse desejo de não se ver associado a atitudes supersticiosas (na partida de Pip do vilarejo) ou de grande demonstração de sentimento (praticamente em todas as cenas que Pip divide com Joe) que denunciariam um quadro de valores oriundos das classes populares - coincidentemente muito próximos ao das crianças. Nessa equiparação, aliás, relembramos o percurso axiomático do primitivismo a infância, explicitado anteriormente neste artigo.

A grande cisão decorrente do processo de crescimento para a vida adulta seria, como observa Andrews, a supressão de características infantis importantes para uma vida interior equilibrada como na visão de Dickens, a imaginação, a expontaneidade e o sentimento de uma solidariedade humana que ultrapassava os limites estreitos ditados pelo trabalho, ascensão social e progresso material. Tais limites podem levar um adulto a romper totalmente com sua porção criança e resvalar num ser moralmente disforme, como Dickens tematiza no conto $A$ Christmas Carol [Conto de Natal] em que três fantasmas assombram o avaro e implacável Scrooge para fazê-lo lembrar-se das qualidades que ele possuía quando criança e jovem, e que haviam sucumbido a sua ruptura dos sentimentos e valores que possuíra. O significado simbólico desse conto será trabalhado com mais profundidade e extensão nos romances a partir de David Copperfield, mas desde então havia, na narrativa dickensiana, esse componente temático a mostrar às personagens adultas específicas de que uma ruptura extrema entre a criança nelas internalizada e seu lado propriamente adulto traria desajustes para suas personalidades. O equilíbrio entre as duas porções da personalidade humana passa a ser, analisando-se o caráter estético-ideológico que recobre as narrativas, uma das linhas mestras da visão artística de Dickens: 
[...] For in Dickens's view it is always open to us as adults to live in harmony not only with children but also with the vestigial childlike side of our own natures. The world of childhood is within easy reach, therefore, and Dickens devotes much of his career to helping his contemporaries to identify and retrieve it. It can be located in those "nurseries of fancy", in the Poetry of Science and in "the romantic side of familiar things" on which his fiction so deliberately dwells, and on which his occasional writings so often insist. That mixed genre of romantic realism generated by this missionary purpose is the hallmark of Dickens's fiction and wholly intentional as a part of his programme for cultural reform.

Esse zelo reivindicatório de um lugar para a criança - na sociedade e nas personalidades - no que ela apresenta de valores mais facilmente suplantados em vista das exigências crescentes dos processos sociais envolvidos na passagem para a vida adulta e maturidade, fundamenta - assim se nos parece - a versátil oscilação entre os focalizadores criança e adulto que Great Expectations apresenta ao longo de toda a narrativa. A contenção do focalizador adulto ao narrar sua história, através do tom sombrio que se mantém após trechos de humor ou de autoironia do Pip maduro, colabora para a tensão entre o narrar do jovem que ascendeu socialmente e que somente se importava com a realização de seu sonho romântico para fazermos um resumo esquemático, e o narrar do homem maduro que percebe não somente a veleidade das aparências e o jogo de poder e ambição que movimenta até mesmo boas intenções, mas também a natureza verdadeira de pessoas honestas e dignas, que mantêm a sensibilidade - afinada com a criança internalizada - integrada a uma maturidade de vida guiada por princípios morais sólidos.

A figura que surge dessa integração é aquela que Malcolm Andrews denominou de "grown-up child", ou seja, uma criança que, tendo se tornado adulta e amadurecida, conseguiu preservar muitas das qualidades infantis nesse processo. Nas suas palavras:

The peculiar energy in his [Dickens's] writing is generated by a dynamic interaction between child-view and adult-view, in which each is interminably checking the other's tendency to domination, to claiming ultimate authority. [...] The grown-up child in that manifestation is neither a childish adult nor a precociously mature child (though Dickens offers us many versions of these and other permutations, as we have seen), but an

Andrews. op. cit., p. 173.

Mediações - Revista de Ciências Sociais, Londrina, v. 10, n.1, p. 9-24, jan.-jun. 2005 AS TRANSFORMAÇÕES DO CONCEITO DE INFÂNCIA EM “GRANDES ESPERANÇAS”, DE CHARLES DICKENS Ricardo Maria dos Santos 
adult whose personality the interior child and interior grown-up are endlessly reconstituting, either collaboratively or competitively. (p. 174)

De forma semelhante, as instâncias narrativas representadas pelo narrador Pip focalizado tanto pela lente da criança e do jovem quanto pela do adulto maduro também participam do processo dinâmico pelo qual as percepções diferentes de cada uma das partes tentarão impor sua primazia sobre a outra. Quando Pip é humilhado por Estella na primeira vez que visita Satis House (no capítulo 8), o sentimento de injustiça é focalizado na criança e por ela vividamente descrito - nas palavras selecionadas pelo focalizador adulto, como que auxiliando aquele estado emocional do menino Pip a encontrar uma expressão verbal adequada. Teríamos aqui um exemplo da colaboração entre as percepções infantil e adulta.

Os exemplos de competição entre as duas esferas da personalidade do protagonista se sucedem quando Pip recebe suas promessas de fortuna e suas ações para com Joe e Biddy são confrontadas com aquelas de sua infância. O medo de não estar procedendo de acordo com as convenções para se integrar a uma nova posição social faz o jovem Pip descartar as antigas associações com o ferreiro, mas a consciência da criança se faz ouvir, gerando então, o sentimento de culpa que permeia toda a narrativa de Great Expectations. Tal sentimento ilustra um outro laivo ideológico incrustado no tecido narrativo da obra e amplificado pela caracterização das personagens: o da necessidade de suprimir aspectos que possam desviar a concentração de esforços do indivíduo masculino da obtenção de posição social, riqueza e dos valores associados a um certo espírito prático e empreendedor identificado com o ideal de um homem da classe média (inglesa) bem-sucedido. Vistos em conjunto, tais aspectos praticamente se confundem com a idéia de infância concebida na época, e a ameaça por ela representada explica uma série de atitudes que na ficção dickensiana ficam manifestas pelo comportamento de personagens que a levam ao extremo, como Mr. Murdstone em David Copperfield, e que embasa muito da ação do jovem Pip no seu aprendizado do mundo adulto de um gentleman. Andrews assim resume essas atitudes:

Middle-class Victorian culture encouraged the maturing male systematically to betray and abandon his own childhood. We have looked at some of the fiction in which Dickens, aware of such patterns of betrayal, 
pursues the theme of reconnection and reconciliation. [...] The novels from David Copperfield onwards carry this theme forward in an enlarged critique of English society and cultural values, by gradual disclosure of the vast and intricate web of connections suppressed by those whose positions of worldly power depend precisely on maintaining such suppression. (p. 180)

A figura que mais se fará presente na lembrança de Pip nesses momentos em que resquícios de aspectos nobres da criança reclamam a atenção do adulto é justamente Joe Gargery. No começo do romance, Pip diz que via o ferreiro como "a larger species of child, and as no more than my equal" (cap. 2, p. 40) amizade entre os dois e da solidariedade entre eles perante os desmando de Mrs. Joe que o garoto pode sentir-se amado e, especialmente quando começa a escrever, valorizado. As características simplórias de Joe encobrem a nobreza de seus sentimentos, a estabilidade de seu afeto por Pip, a serena e resoluta aderência a princípios de verdade e respeito que, mesmo quando o protagonista era criança já o impressionavam pela sabedoria daquele homem tão simples como na fala do menino começando a entender o senso de justiça de Joe:

Young as I was, I believe that I dated a new admiration of Joe from that night. We were equals afterwards, as we had been before; but, afterwards at quiet times when I sat looking at Joe and thinking about him, I had a new sensation of feeling conscious that I was looking up to Joe in my heart. (p. 80)

A figura exemplar de Joe também apresenta outros traços valorizados por essa cultura em torno da concepção de um ideal masculino, como o da grande força física e o controle para somente usá-la como agressão quando não houver outra solução. No entanto, essa característica é totalmente subordinada a docilidade de seu temperamento e a afetuosa exuberância de sua natureza generosa; tal combinação também fora captada pelo olhar emocionado do adolescente Pip - embora talvez somente compreendido pelo Pip maduro:

Joe laid his hand upon my shoulder with the touch of a woman. I have often thought him since, like the steam-hammer, that can crush a man or pat an egg-shell, in his combination of strength with gentleness. [...] (p. 168)

\footnotetext{
${ }^{3}$ Dickens, C. Great Expectations. Ed. Angus Calder. Harmondsworth: Penguin, 1965. Todas as referências à obra doravante se baseiam nessa edição.
} 
Nesse trecho, incidentemente observa-se a associação da delicadeza com o toque feminino, que em termos convencionais para a época não seria uma característica aprovada nos homens, mas que tem o potencial assim como a ferramenta a vapor do ferreiro de servir ao indivíduo de diferentes maneiras, de acordo com sua sensibilidade e destreza. O que está figurativizado aqui remete também a um modelo de ideal masculino ${ }^{4}$ que seria a transição entre um tipo permissivo da alta sociedade inglesa do século XVIII e aquele representado pelo "dandy" do período da Regência (1811-1820) do Príncipe de Gales, George IV:

The new model of manliness and gentlemanliness that Dickens inherited in the later 1830s and the 1840s was a product of these reactions: this type was anti-Dandiacal, earnest and sensitive. The older manliness of the Georgian gentry promoted hard drinking and libertinism. The new model promoted sobriety, chastity and a greatly increased respect for women.

Dessa forma, a combinação de características de ingenuidade e autocontrole, coragem e compaixão, gentileza e força constituía um modelo de atitude masculina em desenvolvimento no imaginário da sociedade vitoriana do período préimperialista (após esse período, um novo modelo ganhará forças: o do homem que não demonstra suas emoções em público e mantém um comportamento impassível diante da vida). A sensibilidade de Joe, além de iluminar esse aspecto do ethos social, demonstra principalmente a conexão mantida com traços da criança que ele não eliminou - geralmente aqueles tido como "femininos" também. A infância de Pip, nesse contexto, pode aproveitar do natural amparo e compreensão da personalidade de Joe - fortalecida emocionalmente pela presença de forças aparentemente contraditórias em equilíbrio. Embora Pip tenha de perseguir seus próprios ideais, a estatura moral e a riqueza afetiva de Joe se tornam pontos de referência cada vez mais fortes para Pip, a medida que ele amadurece. As qualidades que ele também pretende desenvolver em si mesmo se espelham no exemplo de Joe, que se configura, na narrativa, uma criança crescida por excelência:

\footnotetext{
4 "Ideal masculino" é nossa versão para "manliness", que se opõe nos textos de Andrews, a "masculinity", entendida como a virilidade na sua acepção de comportamento social esperado e admirado nos homens, tendo portanto, um aspecto fortemente marcado pela aparência e pelas regras de cada grupo social em determinado período.

Andrews, op. cit., p. 92.
} 
Like Tom Pinch, Joe can display a strong sympathy with children as well as a childish strain in his own character; and these traits are presented as quite compatible with a fully adult sense of responsibility and a moral seriousness. He is perhaps the most impressive example in Dickens of a man who blends in himself a childlike simplicity and openness with a mature wisdom and humanity. He is an exemplary grown-up child.

\section{Conclusão}

Da interação de fatores como a caracterização das personagens, a complexidade do componente ideológico exposto acima e a focalização diferenciada do narrador resulta a especial construção literária de Pip. Deve-se observar também, como as transformações do papel da criança e do conceito de infância na sociedade vitoriana estão subjacentes ao trabalho artístico do autor. $O$ texto busca conciliar através da categoria da criança crescida, o complexo ideológico que se encontrava em mutação naquele período da história inglesa no que se refere a criança, e sua expressão na obra, intensificada pelo tom quase que melancólico da narração aponta para questões de evolução psicológica que devem acompanhar a evolução moral e social dos cidadãos de classe média do século XIX. A própria percepção do valor atribuído às qualidades infantis a serem preservadas no adulto encontra no romance um histórico de negligência que é recuperado pelo protagonista Pip, no final da narrativa como parte de seu aprendizado ético e de seu amadurecimento - e o olhar de Dickens para com a infância antecipa,em muitas décadas, a importância que a ficção - e a sociedade da era moderna - têm dado ao status da criança.

Andrews, op. cit., p. 96.

Mediações - Revista de Ciências Sociais, Londrina, v. 10, n.1, p. 9-24, jan.-jun. 2005 AS TRANSFORMAÇÕES DO CONCEITO DE INFÂNCIA EM “GRANDES ESPERANÇAS”, DE CHARLES DICKENS Ricardo Maria dos Santos 